\title{
AUTOETNOGRAFIA: UM CAMINHO METODOLÓGICO PARA A PESQUISA EM ARTES PERFORMATIVAS
}

\author{
AUTOETHNOGRAPHY: A METHODOLOGICAL WAY \\ FOR RESEARCHING PERFORMATIVE ARTS
}

AUTOETNOGRAFÍA: UN CAMINO METODOLÓGICO PARA LA INVESTIGACIÓN EN ARTES PERFORMATIVAS

\section{Camila Matzenauer dos Santos Gisela Reis Biancalana}

Camila Matzenauer dos Santos Mestranda no Programa de Pós-Graduação em Artes Visuais da Universidade Federal Santa Maria (UFSM) e bolsista CNPQ. Bailarina, performer e coreógrafa na Umbigo de Bruxa - Virações Artísticas.

Gisela Reis Biancalana

Professora doutora do curso de Bacharelado em Dança e membro permanente do Programa de Pós-Graduação em Artes Visuais na Universidade Federal de Santa Maria (UFSM). Pesquisadora em performance, arte e cultura. Atua como performer, diretora e docente-pesquisadora. 


\section{Resumo}

Este artigo discorre acerca do método de pesquisa autoetnográfico aplicado a um fazer artístico performativo em desenvolvimento no mestrado em Artes Visuais. Neste contexto, o trabalho é acompanhado e, consequentemente, atravessado colaborativamente pela artista docente-pesquisadora que orienta a investigação. O percurso reflexivo desenvolvido ancora-se em diferentes autores, como Laplantine, Fortin e Cattani, para abordagem deste procedimento metodológico e sua aplicação em duas performances: Diane e Yasmin.

Palavras-chave: Criação, Metodologia, Performance.

\section{Abstract}

This article discusses the autoethnographic research method applied to an artistic performance developed by the masters' Visual Arts program. In this context, the work is monitored and, consequently, collaboratively crossed by the teacher-researcher artist who guides the investigation. The reflexive course developed is anchored in different authors, such as Laplantine, Fortin and Cattani, to approach this methodological procedure and its application on two performances: Diane and Yasmin. Keywords: Creation, Methodology, Performance.

\section{Resumen}

Este artículo reflexiona sobre el método de investigación autoetnográfico aplicado a un hacer artístico performativo en desarrollo en la maestría en Artes Visuales. En este contexto, el trabajo es acompañado por y, consecuentemente, recibe aportes de la artista docente-investigadora que orienta la investigación. El recorrido reflexivo desarrollado se basa en los trabajos de diferentes autores como Laplantine, Fortin y Cattani, para abordar este procedimiento metodológico y su aplicación en dos performances: Diane y Yasmin.

Palabras clave: Creación, Metodología, Performance.

Este artigo apresenta uma discussão acerca do método autoetnográfico inserido em um processo de criação em performance, arte que se instaura na relação colaborativa estabelecida pelo acompanhamento da artista-docente. Desse modo, a metodologia será delineada, descrevendo-se algumas das suas possibilidades de aplicação e sua potência, sobretudo, em relação à 
pesquisa artística no âmbito acadêmico. Inicialmente, considera-se pertinente trazer uma breve introdução sobre no que consiste o método etnográfico, a fim de elucidar a compreensão sobre o referido procedimento metodológico e sua aplicação via processo colaborativo. Em seguida serão abordadas duas de uma série de performances realizadas durante os anos de 2016 e 2017 e desenvolvidas com base nessa metodologia.

Primeiramente, a etnografia tem origem nas ciências sociais e é entendida como método de pesquisa que valoriza a dimensão sociocultural dos acontecimentos estudados. Assim, segundo o antropólogo francês François Laplantine (1996, p. 149), entende-se que "provém de uma ruptura inicial em relação a qualquer modo de conhecimento abstrato e especulativo, isto é, que não estaria baseado na observação direta dos comportamentos sociais a partir de uma relação humana". Isso justifica o fato de o método ser significativamente utilizado por antropólogos, sobretudo no que diz respeito a pesquisa de campo, visto que ele "não consiste apenas em coletar, através de um método estritamente indutivo uma grande quantidade de informações, mas em impregnar-se dos temas obsessionais de uma sociedade, de seus ideais, de suas angústias" (Ibid.).

A partir dessa compreensão inicial sobre o método etnográfico, Versiani (2005) escreve acerca do neologismo possivelmente vislumbrado na palavra autoetnografia, o qual teria sido proposto para caracterizar uma forma diferente de etnografia em que, segundo o autor, o prefixo auto serviria para

impedir a tendência à supressão das diferenças intragrupos, enfatizando as singularidades de cada sujeito - autor, enquanto o termo etno localizaria, parcial e pontualmente, estes mesmos sujeitos em um determinado grupo cultural. Assim poderíamos pensar em autoetnografias como espaços comunicativos e discursivos através dos quais ocorre o 'encontro de subjetividades', a interação de subjetividades em diálogo. (lbid., p. 87)

Logo, observação e descrição seguem presentes, contudo, o pesquisador passa a compreender-se também como parte do seu foco de estudo.

Segundo os autores Cano e Opazo (2014, p. 149), o antropólogo Karl G. Heider foi um dos primeiros a utilizar o termo autoetnografia ao designar, em 1975, as descrições que o grupo humano o qual estudava fazia de sua própria 
cultura. Ainda de acordo com Cano e Opazo (2014, p. 149), David Hayano utilizou o mesmo termo em 1979 para referir-se "ao estudo da cultura a que o pesquisador pertence".

Atualmente, segundo Ellis, Adams e Bochner, citados por Cano e Opazo (2004, p. 149), a autoetnografia comumente diz respeito a um modo de pesquisa em que se busca "valorizar a experiência do pesquisador através da descrição e análise sistemática para a maior compreensão dos aspectos do contexto ao qual pertence ou em que participa". Ou seja, enquanto Versiani fala sobre a presença das subjetividades como característica desse método, a última citação enfatiza novamente descrição e análise sistemática como ferramentas organizacionais importantes para a aplicação da autoetnografia na pesquisa.

Para estudar melhor esse método e encontrar formas de aplicá-lo à pesquisa em diferentes perspectivas, os autores Cano e Opazo (Ibid., p. 143) apresentam algumas possibilidades de subclassificações da autoetnografia. Assim, pode-se compreendê-la enquanto formadora, informadora, heurística, descritiva, analítica e crítica, como será descrito na sequência.

Entende-se autoetnografia como formadora de uma investigação muito mais em formato de memória ou memória crítica, visto que nesse momento as informações não são submetidas a análises, interpretações e tampouco se articulam a conhecimentos de outras fontes. Ela pode ser considerada informadora quando dados e textos autoetnográficos são usados como fonte de informação tão relevante quanto as oriundas de outras fontes, como livros, revistas etc. - lembrando que essas informações serão analisadas e processadas a seguir. Também pode ser heurística quando é usada para refletir as diferentes etapas do processo de pesquisa, interessando-se muito mais por ele do que pelos resultados. Já na autoetnografia descritiva, como sugere o nome, o autor apresenta a pesquisa de modo descritivo, sem tanto aprofundamento, a qual pode ser entendida como investigação preliminar que, posteriormente, será melhor desenvolvida. Em um segundo momento, ela passa a assumir um viés crítico; nesse ponto, a autoetnografia analítica volta-se para a reflexão acerca da pesquisa e cria conhecimento a partir do assunto/objeto ou da temática em questão. 
Devido ao fato de valorizar a experiência do pesquisador sem desvincular suas impressões e intenções da pesquisa, compreende-se que elementos autobiográficos se fazem presentes no método autoetnográfico. Porém, é importante que haja diferenciação entre autobiografia e autoetnografia. Enquanto a primeira se restringe a descrever acontecimentos sobre aquele que escreve, a segunda insere um viés etnográfico, buscando relacionar o pessoal à cultura para o estudo e compreensão desta.

Fortin (2009, p. 83) contribui com esse pensamento quando inserido em universos artísticos ao entender que "a história pessoal deve se tornar o trampolim para uma compreensão maior.' Ou seja, é preciso que haja um cuidado para que a pesquisa não se reduza apenas à experiência do pesquisador, tornando-se um discurso egocêntrico e esvaziado, que poderia empobrecê-la. Pelo contrário, a experiência deve ser uma forma de potencializar a pesquisa, apresentando outras perspectivas sobre um tema. Ao mesmo tempo, a autora lembra que não há como um discurso ser neutro, afinal, o pesquisador o desenvolve, também, a partir de suas percepções.

Relações entre artes performativas e antropologia não são novas. Como exemplos, pode-se citar Jerzy Grotowski, que desenvolveu estudos culturais com seus atores; Richard Schechner, que manteve forte parceria com o antropólogo Victor Turner, a partir da qual estabeleceu as bases de seus estudos da performance; Eugenio Barba, que cunhou o termo "antropologia teatral" devido a suas investidas nos saberes de culturas diversas; Jean-Marie Pradier, que, por sua vez, ancorou suas investigações naquilo que veio a chamar de etnocenologia, entre outros.

A partir da descrição acerca do método etnográfico, é possível encontrar vários elementos comuns e pertinentes para a pesquisa em artes. Entre eles, destacam-se a constante observação sobre si e o meio (que pode ser entendido como o espaço da criação, por exemplo), a valorização do processo, a presença das subjetividades e do sensível etc. Assim, pode-se apontar o método autoetnográfico como um caminho possível para a pesquisa em arte, a qual, segundo Sandra Rey (2002, p. 137), "requer de modo agudo o difícil exercício da razão e da sensibilidade".

Assim, este trabalho busca estudar a autoetnografia a partir da pesquisa em desenvolvimento no mestrado em artes visuais, que se propôs a 
realizar uma série de performances calcadas nesse procedimento aplicado em um viés colaborativo. Portanto, o estudo meticuloso dessa metodologia foi pensado, aqui, para a pesquisa artística. A performer-pesquisadora encontrou na autoetnografia um caminho para o desenvolvimento de sua pesquisa na pós-graduação, a qual propõe estudar a passagem do tempo no universo feminino através da criação de performances artísticas construídas colaborativamente.

Para tal, foram realizadas pesquisas de campo com o intuito de aproximar a pesquisadora dos diferentes contextos socioculturais nos quais muitas mulheres estão inseridas. É importante ressaltar que, alicerçada ao referencial teórico que sustenta esta pesquisa, a passagem do tempo em relação ao universo feminino será abordada a partir de sua visão pessoal em relação ao convívio estabelecido durante as pesquisas de campo somada ao compartilhamento colaborativo da artista-docente-orientadora. Esse procedimento, consequentemente, reverbera possibilidades para os processos de criação das performances criadas. Desse modo, a pesquisadora traz elementos etnográficos ao propor a pesquisa de campo. Porém, direciona-se à autoetnografia ao enfocar em como sua experiência se insere na pesquisa, tanto em seu fazer artístico quanto na relação estabelecida com as mulheres no momento do levantamento de dados.

Para abordar com mais profundidade essa perspectiva, foram realizados, ainda, estudos sobre o conceito de experiência pela visão de Bondía (2002, p. 28), o qual enfatiza que "o saber da experiência é um saber particular, subjetivo, relativo, contingente, pessoal," elementos que também fundamentam a autoetnografia. A experiência é única para quem a vive e, por mais que duas pessoas passem pela mesma situação, suas experiências serão diferentes. Do mesmo modo, na reflexão acerca da pesquisa artística, mesmo que seja realizada uma investigação sobre um mesmo assunto, os resultados serão diferentes, pois as visões, caminhos, descobertas e resultados de cada pesquisador serão distintos. Pode-se, então, analisar a coleta de dados por esse viés, não só em relação à pesquisa citada, mas de modo geral, reconhecendo o quanto é impregnada de subjetividades e reflete as impressões-sensações de quem pesquisa.

Assim, ao compreender-se como sujeito disponível e aberto da experiência, a artista busca atentar aos detalhes daquilo que vai além das palavras 
ditas, pois não interessam, aqui, os dados quantitativos (Ibid., p. 27). A coleta se dá pelo contato com o que de algum modo a toca: os gestos, as expressões faciais, as expressões corporais, o tom de voz, as memórias e as histórias dessas mulheres. Portanto, interessa às pesquisadoras aquilo que corresponde às suas inquietações e questionamentos, assim como o que elas têm a mais para oferecer. Desse modo, a autoetnografia mostra-se como um caminho interessante para o desenvolvimento desse trabalho ao valorizar a experiência da artista no processo criativo e na pesquisa de campo - aqui, ela estuda suas próprias relações culturais com o meio, ao mesmo tempo que este trabaIho se reverbera pela relação colaborativa com a artista-docente-orientadora.

Para contribuir com essa reflexão acerca da criação artística, busca-se expor de que modo a colaboratividade tem sido um possível caminho. Assim, na sequência, será descrito o processo de criação de duas performances desenvolvidas pela artista e submetidas ao cruzamento colaborativo. No contexto de pesquisa em poéticas da criação, procurou-se trabalhar o papel do orientador como acompanhador e, algumas vezes, como coautor das obras - tal parceria tem contribuído, estimulado e fomentado a prática artística ao repensar determinadas hierarquias históricas presentes no meio artístico e acadêmico. Papéis definitivos de diretor e de ator, de coreógrafo e de bailarino, e mesmo de artistas visuais cujo trabalho é solitário em ateliês têm sido reavaliados desde meados do século XX. Portanto, emergem das recentes discussões termos como coletivo e colaborativo entre os mais visitados na área de artes.

Desse modo, é pertinente discutir o termo colaboração, aqui dirigido por uma realidade mais complexa do que a simples ideia de cooperação. Segundo Biancalana (2017), trata-se de uma relação paradoxal entre coprodutores que afetam uns aos outros. Os colaboradores não questionam uma autoridade óbvia nem pretendem utópica igualdade, pelo contrário, este trabalho pensa na participação da artista-docente-orientadora e em sua relação estabelecida com a criadora. Tal relação esclarece que valores como lideranças e experiências são compreendidos, mas desprendem-se da arrogância e do poder absoluto, incondicional e até, muitas vezes, esvaziado - mesmo porque a igualdade seria padronizante, atitude que "se afasta das perspectivas de ser no mundo contemporâneo que absorvem a instabilidade, o risco, o 
erro, a pluralidade, a diversidade, as múltiplas dimensionalidades do espaço e do tempo" (Ibid., p. 815). De acordo com a autora, a

colaboração não busca um sistema de trocas de posses, mas de fluxo onde as posições estáticas de manutenção do poder são evitadas. Todo processo colaborativo tende a começar e terminar em estruturas fragmentadas. Em última instância os trabalhos colaborativos são dirigidos pelo desejo de lidar com a diferença em liberdade de produção e recusam o poder absolutista das organizações. Ele carrega um imenso potencial social como uma forma de realização e experiência de criação ilimitadas. (Ibid.)

Um dos processos compartilhados pelo grupo consistiu na elaboração de performances artísticas individuais, as quais integraram uma exposição de corpos-arte denominada ExposiAção. Para o desenvolvimento dessa criação, a professora-coordenadora do grupo pediu que os estudantes escolhessem questões instigantes. A artista-pesquisadora em questão, que versa sobre a temática do feminino recorrente em suas obras, teve como mote da criação o uso da pílula anticoncepcional, tida quase como imposição social mesmo com os inúmeros prejuízos causados à saúde da mulher. A escolha por esse tema buscou questionar em que momento a pílula, inicialmente considerada uma libertação feminina, tornou-se mais uma das prisões impostas à mulher. A responsabilidade da contracepção recai sobre a mulher e, no caso do anticoncepcional, pode acarretar danos sérios a sua saúde. Desse modo, a artista foi em busca de informações sobre o uso dessas pílulas que abordassem o tema para dar embasamento à criação da performance.

À medida em que as questões temáticas ficaram mais definidas, a artista começou a estruturar formalmente a performance pela construção de matrizes de ações. Foi nesse momento que o material pesquisado começou a se fundir às impressões de cada uma das artistas. Essa etapa da criação trouxe a materialidade das pílulas para a performance, tendo em vista que, consonante com o pensamento de Glusberg (1987), as performances apropriam-se de signos - dos cotidianos aos mais complexos. Do mesmo modo, a artista apropriou-se dos elementos encontrados nos seus estudos para a construção de um discurso. As performances foram compartilhadas com a artista-docente-orientadora ainda em fase inicial, e o olhar externo, contaminado pelos relatos dos atravessamentos da experiência em campo, colaborou para a construção das 
obras através de trocas, impressões, sugestões e questionamentos. Enquanto uma performance era apresentada, a colaboração funcionava como uma visão externa, verificando a coerência das organizações poéticas construídas em relação aos questionamentos propostos. Dessa maneira, a abordagem estética, os elementos formais selecionados e suas ações performativas foram se transformando em decorrência dessas interferências.

Após as trocas estabelecidas, foi possível definir a ação performativa que resultou em uma movimentação simples, evitando excessos de informações e tornando clara a expressão-comunicação com o público. A partir disso, buscou-se explorar um discurso em performance que buscasse "a eliminação de um discurso mais racional e a utilização mais elaborada de signos" (COHEN, 1989 , p. 66), almejando proporcionar uma leitura subjetiva da obra sem submetê-la a uma narrativa limitada. Com a proposta performativa estruturada, ela foi nomeada de Diane, referência a uma marca conhecida de anticoncepcionais. Essa escolha se deu tanto em alusão às pílulas quanto àquelas que as consomem e, muitas vezes, sofrem com seus efeitos colaterais.

Todo esse processo, calcado no estudo dos malefícios psicofísicos do medicamento, desde a criação até a apresentação da obra, afetou a performer, tendo em vista o fato de ela também ser uma consumidora precoce. Além disso, a artista-pesquisadora também teve contato com mulheres cujas vidas foram afetadas em virtude do uso de pílulas anticoncepcionais. Sendo assim, buscou-se dar sequência a essa investigação artística compreendendo a obra Diane como parte do processo criador da nova performance intitulada Yasmin, obra que apresenta o momento no qual a própria performer interrompe o uso desse método contraceptivo. Durante o processo de criação da obra Yasmin, não houve tantas interferências como no anterior, visto que o trabalho partiu da própria performance Diane. Nesse momento, as reflexões iniciais já constituíam o elemento disparador das questões levantadas. Assim, o viés autoetnográfico ficou evidente em ambas as performances, tendo em vista que a vivência e a experiência da performer e a ação colaborativa que interferiu na obra se fazem presentes ao destacar como questões pessoais suas desdobram-se em assuntos e questões de âmbito maior, os quais, por sua vez, afetam outras pessoas.

Como citado anteriormente, a pesquisa em arte possui especificidades, e é importante que sejam reconhecidas. Algumas vezes o espaço acadêmico 
pode ser entendido como limitador para a pesquisa artística devido a suas exigências e formalidades, no entanto, Cattani (2002) mostra que pode ser justamente o contrário. O meio acadêmico pode colaborar para o desenvolvimento e a consciência das especificidades da pesquisa em artes, trazendo como exemplo a utilização de metodologias coerentes com a proposta criadora. Para a autora, encontrar "uma metodologia de trabalho que ajude a expressar o que se quer, da forma que se quer e manter o espírito investigativo sistemático são maneiras de aprofundar e enriquecer a obra, ampliando a sensibilidade e a qualidade do processo criativo" (Ibid., p. 39).

Através do pensamento de que as obras de arte devem estar presentes na pesquisa ao invés de usadas apenas como ilustração de teorias (Ibid., p. 37), visualiza-se o método autoetnográfico como modo de potencializar a pesquisa em artes. Ele tem sido meio de valorizar a experiência da artista na criação da obra, fazendo com que o público se aproxime mais do processo e compreenda, desse modo, arte e artista como protagonistas. Ao mesmo tempo, a artista tem tomado consciência aprofundada do trabalho que desenvolve pela constante reflexão de si na relação entre seu foco de pesquisa e sua obra.

Dessa forma, a partir do estudo do método e dos exemplos apresentados, é interessante pensar como o uso de autores e de procedimentos de diferentes áreas pode acrescentar à pesquisa em arte, permitindo outros olhares sobre ela. Além disso, investigações autoetnográficas e artísticas apresentam características parecidas, facilitando a relação entre si: o mesmo corpo que cria, vai a campo, escreve e pesquisa. Do mesmo modo, no mundo contemporâneo plural, multifacetado e atravessado por redes de relações múltiplas, os processos colaborativos apresentam-se como perspectiva agregadora de saberes. Assim, entende-se que a pesquisa acontece de forma orgânica, processual e não causal, e que a experiência do artista-pesquisador é indissociável de sua obra e seus estudos.

\section{Referências bibliográficas}

BIANCALANA, G. R. Trabalhos conjuntos e processos colaborativos. In: CONGRESSO DA ABRACE, 9., 2017, Uberlândia. Anais... Uberlândia: UFU, 2017. p. 805-823. BONDÍA, J. Notas sobre a experiência e o saber da experiência. Revista Brasileira de Educação, Rio de Janeiro, n. 19, p. 20-28, jan./abr. 2002. 
CANO, R. L.; OPAZO, U. S. C. Investigación artística en música: problemas, métodos, experiencias y modelos. Barcelona: Fonca-Esmuc, 2014.

CATTANI, I. B. Arte contemporânea: o lugar da pesquisa. In: BRITES, B.; TESSLER, E. (org.) O meio como ponto zero: metodologia da pesquisa em artes plásticas. Porto Alegre: Editora da UFRGS, 2002. p. 35-50.

COHEN, R. Performance como linguagem. São Paulo: Perspectiva, 1989.

FORTIN, S. Contribuições possíveis da etnografia e da auto-etnografia para a pesquisa na prática artística. Revista Cena, Porto Alegre, n. 7, p. 77-88, 2009.

GLUSBERG, J. A arte da performance. Tradução Renato Cohen. São Paulo: Perspectiva, 1987.

LAPLANTINE, F. Aprender antropologia. São Paulo: Brasiliense, 1996.

REY, S. Por uma abordagem metodológica da pesquisa em artes visuais. In: BRITES, B.; TESSLER, E. (org.). O meio como ponto zero: metodologia da pesquisa em artes plásticas. Porto Alegre: Editora da UFRGS, 2002. p. 123-140.

VERSIANI, D. B. Autoetnografias: conceitos alternativos em construção. Rio de Janeiro: 7Letras, 2005.

Recebido em 15/09/2017

Aprovado em 08/11/2017

Publicado em 03/05/2018 